\title{
Communication after mild traumatic brain injury - a spouse's perspective
}

\author{
Samantha Jayne Crewe-Brown \\ Alexandra Maria Stipinovich \\ Ursula Zsilavecz \\ Department of Communication Pathology, University of Pretoria \\ Correspondence to: A M Stipinovich(alex_stipinovich@telkomsa.net)
}

\begin{abstract}
Individuals with mild traumatic brain injury (MTBI) often perform within normal limits on linguistic and cognitive assessments. However, they may present with debilitating communicative difficulties in daily life. A multifaceted approach to MTBI with a focus on everyday communication in natural settings is required. Significant others who interact with the individual with MTBI in a variety of settings may be sensitive to communicative difficulties experienced by the individual with MTBI. This article examines communication after MTBI from the perspective of the spouse. A case study design was implemented. The spouses of two individuals with MTBI served as the participants for this study. Semi-structured interviews were held, during which each participant was requested to describe the communication of their spouse with MTBI. The content obtained from the interviews was subjected to a discourse analysis. The results show that both participants perceived changes in the communication of their spouse following the MTBI. The results further show that MTBI affected communication of the two individuals in different ways. The value of a 'significant other' in providing information regarding communication in natural settings is highlighted. The implications of these findings for the assessment and management of the communication difficulties associated with MTBI are discussed.
\end{abstract}

Keywords: mild traumatic brain injury, spouse's perceptions, communicative competence, discourse analysis, social interaction

Mild traumatic brain injury (MTBI) is said to account for the majority of patients admitted to hospital with brain injuries (Cassidy et al., 2004), representing the greater population of all treated traumatic brain injuries worldwide (Tay, Ang, Lau, Meyyappan \& Collinson, 2010). To date, the majority of research in the area of traumatic brain injury (TBI) has focused on severe TBI (King, Hough, Walker, Rastatter \& Holbert, 2006b). Despite an increased awareness of MTBI, this therefore is the least understood form of brain injury (King et al., 2006b). The majority of behavioural research in the field of MTBI to date has been neuropsychologically based (Duff, Proctor \& Haley, 2002) with the impact of MTBI on communicative competence remaining largely unknown (Whelan, Murdoch \& Bellamy, 2007).

MTBI is associated with a constellation of symptoms, including physical, cognitive, emotional and behavioural symptoms, that vary in terms of degree and rate of recovery after injury (Tay et al., 2010). The cluster of symptoms following MTBI has been coined the postconcussive syndrome (PCS) (Alexander, 1995) and has been reported in up to $50 \%$ of individuals who sustained an MTBI (Satz et al., 1999). The majority of individuals who sustain an MTBI show spontaneous and complete post-injury recovery within a few weeks to a few months. However, some continue to present with symptoms after this time, with approximately $15 \%$ of these individuals complaining of disabling symptoms for as long as 1 year after sustaining their injury (Alexander, 1995; Duff et al., 2002).

The most common symptoms encountered after MTBI may be grouped into three categories: (i) cognitive complaints (including difficulties with memory, attention and concentration); (ii) somatic complaints (including headache, fatigue and sensitivity to noise or light); and (iii) affective complaints (including depression, irritability and anxiety) (McAllister \& Arciniegas, 2002).

As stated above, the majority of behavioural research in this field has been neuropsychologically based (Duff et al., 2002). Neuropsychological sequelae of MTBI have been found to include difficulties with reasoning, information processing, verbal memory and attention to detail, as well as slowed reaction time and reduced error recognition (Kwok, Lee, Leung \& Poon, 2008; Leininger, Gramling, Farrell, Kreutzer \& Peck,
1990; Voller et al., 1999). The frontal lobes of the brain are vulnerable to injury in TBI (McDonald, Flashman \& Saykin, 2002). Given the role that these frontal regions play in the executive functions of regulating and organising behaviour, impulse control, self-monitoring, planning and reasoning skills, even individuals with MTBI demonstrate a strong tendency to exhibit executive dysfunction (McDonald et al., 2002). Impairment in executive abilities may have wide-ranging effects on an individual's ability to function effectively in daily life and can impair job performance, activities of daily living and interpersonal relationships (McDonald et al., 2002). Furthermore, effective communication is reliant on cognitive skills, including attention, memory, word-retrieval ability, the formulation of thoughts, complex information processing and executive functioning (Green, Stevens \& Wolfe, 1997). Even when the medical categorisation is 'mild', the effects of the brain injury may therefore have a severe effect on the person's ability to communicate effectively (King et al., 2006b).

Barrow et al. (2003) warn that current methods of language testing might not provide sufficient cognitive load to expose the subtle difficulties that affect the functional performance abilities of individuals with MTBI. As a result, the identification of individuals with MTBI who might benefit from speech-language therapy remains tenuous. King et al. (2006b) agree, stating that testing procedures must incorporate tasks that are sensitive to the affected skills of individuals with MTBI. The administration of tasks of higher-order linguistic function demanding frontal lobe support has provided better insight into the language disorders associated with TBI (Whelan et al., 2007). Such tasks include reaction time measures examining speed and accuracy of naming, tasks requiring the organisation of substantial quantities of information, the processing of abstract language and the filtering out of environmental interference (Barrow et al., 2003; King et al., 2006b; Mathias, Beall \& Bigler, 2004; Whelan et al., 2007).

Recent research by Whelan et al. (2007) aimed to profile the language abilities of an individual with MTBI using tasks hypothesised to demand frontal lobe support. Difficulties were found in activities requiring complex lexical-semantic operations such as sentence construction, multiple definition formulation, absurdity detection or correction and passive/temporal structure completion (Whelan et al., 2007). In 
addition, research by Barrow et al. (2003), King, Hough, Vos, Walker \& Givens (2006a) and King et al. (2006b) revealed compromised speed of word retrieval in individuals with MTBI during time-pressurised conditions. However, in contrast to the finding of word-retrieval deficits during confrontation naming, King et al. (2006b) found no significant deficits with regard to word retrieval in the discourse of participants with MTBI. They concluded that the increased cognitive load imposed by the speeded task of confrontation naming may have resulted in greater error occurrence than the discourse task did.

Daily work and home activities routinely involve time-pressured situations and multilevel processing (Barrow et al., 2003). This may explain why individuals with MTBI who perform within normal limits on standard linguistic and cognitive assessments often present with debilitating difficulties in communicative and cognitive activities of daily life (Kim et al., 2009; McDonald et al., 2002). According to Whelan et al. (2007), the real-life consequences of subtle cognitivelinguistic impairments after MTBI remain largely unexplored.

The field of pragmatics is concerned with the communicative consequences of various cognitive and linguistic deficits on interaction (Prutting \& Kirchner, 1987). Pragmatic aspects of language are closely linked to judgements of a perceived level of social competence. Social competence requires a complex repertoire of behaviours, including the integration of one's knowledge of the world with cognitive, social, behavioural, psychological and linguistic processes (Hartley, 1995). As communication involves the interaction of the individual with his/ her environment, the environment in which communicative functions occur is considered a major determinant of communicative behaviour. For this reason, communication assessment and rehabilitation requires a multifaceted approach including a focus on everyday communication in natural settings (Galski, Tompkins \& Johnston, 1998; Snow \& Ponsford, 1995).

Functional rating scales designed to determine the effect of deficits upon communicative activities and life participation are available. The Pragmatic Protocol (Prutting \& Kirchner, 1987), for example, is a descriptive taxonomy designed to provide an overall communicative index for school-aged children, adolescents and adults. It consists of 30 pragmatic aspects of language and is completed by the clinician after observing 15 minutes of unstructured, spontaneous interaction between communication partners in a natural setting. According to Lomas et al. (1989), the likelihood that clinician-assessors observe patients in true daily-living situations is slim. For this reason, rating scales that are reliant on reports made after direct observations by a significant other who spends substantial time with the client in a variety of settings are also available. The Communicative Effectiveness Index (CETI) (Lomas et al., 1989) is a functional communication measure for aphasia that gives the clinician first-hand evidence on the communicative performance of the individual with aphasia as observed by a significant other. This scale has also been found to provide a valuable measure of change in functional communication ability (Lomas et al., 1989). A possible disadvantage to using a rating scale to examine communicative competence from the perspective of a family member, however, is that views are directly addressed as opposed to being carefully elicited. This may prevent unexpected and possibly valuable information from being disclosed.

An alternative approach to gaining understanding of an individual within his/her environment is that of discourse analysis (DA). DA is a qualitative approach to the measurement of individuals' perceptions (Vyncke, 2000). In this approach, the content of the discourse obtained during a semi-structured interview is examined. As an individual's choice of words to convey perceptions and experiences gives rise to individual versions of reality (Willig, 1999), DA provides valuable insight into an individual's experience and interpretation of the topic discussed.

In this study, DA was used to examine the perceptions and experiences of spouses regarding the communication of two individuals with MTBI. In so doing, information regarding the impact of MTBI on communication in natural settings was obtained.

\section{Method}

\section{Aim}

The aim of the study was to describe the communication of two individuals with MTBI from the perspective of the spouse.

\section{Research design}

A case study design was selected within the framework of qualitative research. Case studies aim to analyse a situation precisely and in detail in order to provide insight into the phenomenon being investigated (Titscher, Meyer, Wodak \& Vetter, 2000). In this study, information was obtained from two participants through semi-structured interviews, the content of which was subjected to DA.

\section{Participant selection criteria}

The participants in this study were the spouses of two individuals with MTBI. Trauma has been found to have different effects on individuals with differing kinship relationships (Kreutzer, Gervasio \& Camplair, 1994a; Leach, Frank, Bouman \& Farmer, 1994). A common methodological limitation of previous research into family functioning after TBI is that data from relatives with different kinship relations are often combined (Kreutzer, Gervasio \& Camplair, 1994b). In this study, the perceptions regarding the communication of the two individuals with MTBI were therefore confined to the perceptions of the spouse.

The participants were to be proficient in either English or Afrikaans. They should have been living with their spouses for a minimum period of 1 year before the MTBI, ensuring familiarity with their spouse's premorbid communication abilities. Participants were to be residing with the individual with MTBI at the time of the interviews. A description of the participants (referred to as P1 and P2) is included in Table I.

Selection and description of the individuals with MTBI Two individuals with MTBI were selected according to the delineation of MTBI provided by the American Congress of Rehabilitation Medicine (ACRM) (1993). The individuals selected were therefore to have sustained traumatically induced physiological disruption of brain function, manifested by at least one of the following: loss of

\section{Table I. Description of participants}

\begin{tabular}{|c|c|c|}
\hline & P1 & $\mathbf{P 2}$ \\
\hline Gender & Female & Female \\
\hline Primary language & Afrikaans & Afrikaans \\
\hline Number of years of education & 14 & 14 \\
\hline Current occupation & Technologist & Landscaper \\
\hline Occupation at time of spouse's MTBI & Technologist & Landscaper \\
\hline Number of children & Three & None \\
\hline Home environment & House in residential area & House in residential area \\
\hline
\end{tabular}


consciousness (LOC) for up to 30 minutes; any loss of memory regarding events immediately before or after the accident; any alteration in mental state at the time of the accident; and focal neurological deficit(s) that may or may not have been transient. Post-traumatic amnesia (PTA) was not to have exceeded 24 hours after 30 minutes and the initial Glasgow Coma Scale (GCS) score was required to have been 13 - 15, 30 minutes after the injury was sustained.

The majority of individuals with MTBI show complete recovery of their symptoms within 1 - 3 months after injury (Levin et al., 1987, in Alexander, 1995). However, some exhibit persisting difficulties beyond 3 months after injury (e.g. Alexander, 1995; Kwok et al., 2008; Leininger et al., 1990). A further selection criterion was therefore a post-injury interval of 3 months or longer to ensure that any change in communication associated with the injury would have stabilised and become part of the person's communicative repertoire. As stated above, the individuals with MTBI were required to have been living with their spouses (the participants) for a year prior to the injury, and since the injury.

The individuals with MTBI were selected by means of purposive sampling (Strydom, 2005). Patient records from a private hospital as well as patient records from the private practice of a neurologist were examined for individuals who met the selection criteria. Information pertaining to duration of LOC and duration of PTA was not indicated in the hospital records. Individuals were therefore initially selected based on the GCS score alone. Information pertaining to LOC and PTA was obtained from the spouse.

A description of the individuals with MTBI (referred to as MTBI1 and MTBI2) is provided in Table II. The spouse of MTBI1 is P1 and the spouse of MTBI2 is P2. As indicated in Table II, MTBI1 sustained a frontal lobe haemorrhage due to the injury. Individuals with MTBI whose initial injuries include complications such as depressed skull fractures, contusions and subdural or epidural haematomas are more likely to have persistent cognitive deficits. However, the majority of such patients experience resolution of these symptoms, even if only after some delay (McAllister \& Arciniegas, 2002). MTBI1 was included in this study because his GCS score remained within the limits posited for the classification of MTBI, and he had sustained his injury 6 months prior to the interview. According to P1 and P2, LOC was less than 30 minutes. According to MTBI1's spouse (P1), MTBI1 presented with notable word-finding difficulties in the first week after the accident. However, she stated that he was orientated to place and person and that he was aware that he had been in an accident.

\section{Research ethics}

The research was granted ethical clearance by the Research Proposal and Ethics Committee of the Faculty of Humanities, University of Pretoria. The individuals with MTBI and their spouses were provided with a verbal and written explanation of the nature and purpose of the study, and gave written consent confirming their voluntary participation in the study. Those who agreed to participate were assured of confidentiality at all times during the study. The participants were also free to withdraw from the study at any time.

\section{Material and equipment for data collection}

A semi-structured interview was used to obtain the required data, which were then subjected to a DA. DA, as defined by Willig (1999, p. 2) is concerned with, among other things, 'the ways in which language constructs experiences .... People use their discourse to construct versions of their social world (Potter \& Wetherell, 1987). To adequately allow the participants to construct the individual versions of their social worlds, the interview attempted to create a 'conversation encounter', placing equal importance on the interviewee's answers and the researcher's questions (Potter \& Wetherell, 1987, p.165). The researcher provided only two topic-introducing requests, attempting to guide the conversation rather than prescribe neutral and passive questions as in the case of a traditional interview (Potter \& Wetherell, 1987). Following the topic-introducing requests, the researcher proceeded with follow-up questions (e.g. 'Is that all?'), probing questions (e.g. 'OK, tell me a little more about that'), specifying questions (e.g. 'And how did you handle that?'), direct questions (e.g. 'And for how long did that continue?') and interpreting questions (e.g. 'Is that what you mean by ...?'), so as to adequately understand the participants' answers (Kvale, 1996).

The following two topic-introducing requests were presented within the interview:

- Request 1: 'What do you think communication entails?' Communication is a multifaceted commodity encompassing non-verbal and verbal behaviour. Individuals may differ in their judgements regarding appropriateness of social behaviour. Cultural background, for example, shapes values, belief and stereotypes, and influences how individuals react with others (Hartley, 1995). Judgements made by the spouses regarding the communication of the individual with MTBI were likely to be made within the framework of their understanding of communication. By asking this question, attempts were made to obtain an idea of what communication meant for each participant and therefore what would be important for them with regard to their spouse's communication.

\section{Table II. Description of individuals with MTBI}

Date of injury

Time since injury at time of first interview

Glasgow Coma Scale (GCS) score, according to hospital records

Duration of loss of consciousness, according to spouse

Duration of post-traumatic amnesia, according to spouse

Number of years married to/living together with spouse

Primary language

Number of years of education

Occupation prior to MTBI

Employed at the time of interview?

MTBI1 (P1's spouse)
27 September 2003
6 months

$14 / 15$

$<30$ minutes

Orientated to place and person within 24 hours, but presented with notable word-finding difficulties for 4 - 5 days

5.5 years

Afrikaans

12

Unemployed (previously a supervisor in a retail business)

No

MTBI2 (P2's spouse)
24 February 2001
3 years
13/15
$<30$ minutes

$<24$ hours

4 years

Afrikaans

12

Landscaper

Yes 
- Request 2: 'Tell me about your spouse's communication.' In phrasing this request, no reference was made to communication difficulties. In this way, participants were free to comment on either positive or negative aspects of their spouse's communication. No time frame in relation to the MTBI was specified in Request 2. The omission of a time frame gave the participants the freedom to highlight or foreground any information pertaining to their spouse's communication, within the context of their subjective understanding of communication that they felt was relevant at the time of the interview. As the participants were familiar with the individual with MTBI both before and after the accident, it was hoped that any changes that they may have noted in their spouse's communication and which they ascribed to the MTBI would be spontaneously presented. Where necessary, the followup, probing, specifying, direct or interpreting questions described above were asked in relation to the MTBI for the purpose of clarifying the participants' responses.

The conversations were recorded using an Aiwa TP-510 cassette recorder and a Hitachi VM E53E audiovisual cassette recorder for later analysis.

\section{Procedure \\ Pilot study}

A pilot study was conducted to determine the clarity of the proposed topic-introducing requests, the adequacy of the recording equipment, and the time it would take to set up and conduct the interview. The selection criteria stipulated for the main study were used to select a single participant for the pilot study. The two requests posed were found to be understood by the participant. No changes to the questions or data collection and analysis procedures were therefore necessary.

\section{Data collection procedure}

The interviews took place in the participant's home or place of work. Recording equipment was set up as unobtrusively as possible. The individual with MTBI was not present during the recording. The interviews ranged from 30 minutes to 1 hour in length. After completion of the interviews, the researcher analysed the discourse into themes according to the guidelines provided by Potter and Wetherell (1987) and Wetherell, Taylor and Yates (2001). Four weeks after the initial interviews, the participants were re-interviewed by the researcher to ensure that the data collected during the interviews had been interpreted correctly. The re-interview gave the participants opportunity to comment on the researcher's interpretations (Kvale, 1996). In this way, trustworthiness of the results was enhanced (De Vos, 2002; Lincoln \& Guba, 1985).

\section{Data recording procedure}

The data (discourse) from the tape and audiovisual cassettes were transcribed in standard orthography in the relevant language so that the discourse could be easily analysed.

\section{Data analysis procedure}

The content obtained during the interview was subjected to a DA to obtain a qualitative description of the participant's perceptions of the spouse with MTBI's communication. DA examines the content of the conversation, rather than aspects of structural organisation (Jaworski \& Coupland, 1999). DA therefore examines and interprets the meaning behind what is being said in the conversation. The transcription of the interview marks the start of the analysis process. The interviews were transcribed using standard English or Afrikaans orthography. The discourse was read carefully by the researcher, as well as by a second professional with experience in DA, thereby ensuring confirmability and trustworthiness (De Vos, 2002; Lincoln \& Guba, 1985). After reading the transcript repeatedly, the researcher recorded recurring images, words and issues next to the text in the first draft. The words and images used in the discourse were carefully studied and placed into categories based on similarities between them. Themes were then identified within these categories according to the frequency with which they occurred, the information that followed regarding those themes, and the amount of discourse that was linked to each particular theme.
Patterns that occurred within themes were identified and viewed as sub-themes within the main theme.

\section{Trustworthiness}

Lincoln and Guba (1985, p. 290) refer to the 'truth value' (or trustworthiness) of qualitative studies. Measures implemented in this study to ensure trustworthiness included credibility, transferability, dependability and confirmability.

Credibility refers to the accuracy with which the participants are represented and described (Lincoln \& Guba, 1985). To ensure credibility, the individuals with MTBI were selected according to the criteria provided by the ACRM (1993). The individuals with MTBI, their spouses and the data collection and analysis procedures are described in detail. The semi-structured interviews were conducted in the participants' first language to facilitate accurate expression and their responses recorded so that they could be transcribed word-for-word.

Transferability refers to the applicability of the findings to another context or group of people (Lincoln \& Guba, 1985). The purpose of this study was not to generalise the findings to all individuals with MTBI. Multiple variables influence the communication interaction of individuals, including those with MTBI. However, the analysis of communication following MTBI in natural settings is hoped to have relevance to other individuals with MTBI.

Dependability refers to whether or not the findings would be consistent if the enquiry were replicated (Lincoln \& Guba, 1985). Dependability was ensured by implementing a pilot study. Furthermore, a followup interview was held with the participants to provide them with the opportunity to confirm the data and interpretations thereof.

Confirmability, also referred to as neutrality (De Vos, 2002), emphasises the importance of the findings reflecting the questions posed by the study and the participants' responses, rather than the researcher's biases or prejudices. Confirmability was facilitated by providing the opportunity for the participants to define communication. This definition, in turn, formed the context in which their description of the communication of the individuals with MTBI was interpreted. Secondly, the omission of a time frame or reference to communication difficulties in the second topic-introducing question of the semi-structured interview ensured that their responses were in no way influenced by the researchers' bias that MTBI may impact on communication. Opportunity for the participants to confirm the data and the interpretations thereof was facilitated by the implementation of a second interview. A second observer assisted in the interpretation of the data, thereby strengthening confirmability.

\section{Results and discussion Participant 1}

When asked for her view on what communication entails, P1 referred to communication as involving the verbal expression of one's feelings:

... to express yourself ...'

'... to tell someone how you're feeling ...'

P1 also recognised non-verbal components such as body language and facial expression:

'.. like they say "body language"..."

... like how your body can talk and your facial expressions can also be part of communication ...'

P1 further emphasised communication for the purpose of interaction within the context of a relationship:

... you want to communicate with someone ...'

'... to tell someone how you're feeling ...'

In summary, P1's view of communication involved both verbal and non-verbal expression (including expression of emotions) within the context of a relationship. Any changes in MTBI1's communication that impacted on his verbal and non-verbal communication, or any changes 
in his communication that affected their relationship, were therefore likely to be noted by $\mathrm{P} 1$.

When asked to describe MTBI1's communication, P1 commenced by stating that he communicates well. She also mentioned that he is well liked and that he is an extrovert. However, throughout the interview process it became clear that she had noted numerous changes in his communication since the MTBI. Three themes were identified in the DA of P1's description of MTBI1's communication, namely loss of temper, word-retrieval difficulties and role change.

\section{Loss of temper}

P1 stated that MTBI1 communicates well, but that he loses his temper more frequently since the accident:

'No, he communicates well. It's just that his temper ... he sometimes is a little short-tempered with the children ...'

'Yes, he ... it's [MTBI1's temper] a lot shorter than it was before the accident.'

'... it's just that he loses his temper extremely quickly...

The communicative consequence of feelings of anger or irritability may be loss of temper. Loss of temper is therefore considered a form of communication. As P1 considered communication to entail the expression of emotions, any changes in MTBI1's expression of emotions were likely to be noted by $\mathrm{P} 1$.

According to P1, MTBI1's loss of temper affected his ability to communicate and interact effectively with his family. His loss of temper appears to have affected P1's relationship with him as well as his relationship with their children:

'We fight a little more.'

'He sometimes becomes quite ugly with them.' [the children]

Communication-related personality and psychosocial change has been found to profoundly influence an individual's integration back into the family system (Ylvisaker, Szekeres \& Feeney, 2001). Irritability and associated loss of temper is a common symptom in the first 3 months after MTBI, usually resolving thereafter (ACRM, 1993). MTBI1's loss of temper has persisted beyond 3 months. As stated, MTBI1 sustained a frontal haemorrhage. Individuals with MTBI whose initial injuries include complications such as haemorrhage may be more likely to have persistent deficits (McAllister \& Arciniegas, 2002).

Emotional control requires a certain level of arousal. The reticular activating system (RAS) influences the arousal level of the brain. The RAS is sensitive to axonal damage owing to its multiple projections. Decrements in arousal are therefore frequently associated with TBI, resulting in decreased cortical activation necessary for behavioural control. This, in turn, may result in irritability, poor frustration control and increased anger or rage (Hartley, 1995).

P1 mentioned factors that appear to trigger or contribute to MTBI1's loss of temper. These include the use of alcohol, his children and his word-finding difficulties:

'... if he has any alcohol in him then he gets angry, which wasn't really the case before the accident.'

"If the children are here for just an hour or two he will "go off" at one of them ...'

$\therefore$ then he will give her a harder hiding than he ought to, or about something silly that doesn't actually justify a hiding.'

'He basically gets angry if you don't immediately know what he's talking about.'

The RAS, and therefore the brain's arousal state, is influenced by stressors (including alcohol and anxiety). According to Alexander (1995) individuals with MTBI have reported increased sensitivity to modest alcohol use. Symptoms of PCS have been found to increase when individuals with MTBI are placed under stressful conditions (Hanna-Pladdy, Berry, Bennett, Phillips \& Gouvier, 2001), resulting in inappropriate communication in stressful situations (Ylvisaker et al., 2001). The environmental factors (children and alcohol) that are now considered by P1 to contribute to MTBI1's loss of temper were present before his accident. It is possible that, since the MTBI, MTBI1's cortical activation required for behavioural control in the presence of such stressors has been affected.

MTBI1's loss of temper may also be associated with executive dysfunction. The executive control centre is the point of integration of internal and external stimuli (Hartley, 1995). Executive functions within the control centre influence deliberate cognitive, social, academic, vocational and communicative behaviours (Ylvisaker \& Feeney, 1998). Executive dysfunction is a common consequence of MTBI owing to the high incidence of damage to the frontal lobes of the brain (Kim et al. 2009). MTBI1 sustained a frontal haemorrhage. The possibility therefore exists that he sustained injury to his executive control centre, resulting in the excessive display of emotions, evident in his loss of temper.

Of significance in P1's description of MTBI1's loss of temper were her comments that he is remorseful once he has lost his temper with his children and that he does not exhibit this behaviour towards other people:

'He says he often feels sorry right away ... then he will say sorry, and then he feels very bad about it.'

'And he also won't easily become aggressive with other people.'

MTBI1 therefore appears to possess some insight into his behaviour as well as the ability to perceive situations, to integrate these perceptions with stored knowledge, to determine a possible course of action and then to monitor his behavior in certain situations. These are all functions of the executive control centre (Hartley, 1995). However, in the presence of stressors (such as alcohol or his children), he appears less able to exert control over his behaviour.

MTBI1's ability to exert control over or adapt his communication interaction to suit certain contexts and certain communication partners supports the notion that social competence cannot be interpreted unless communication and context are treated simultaneously (Prutting, 1982). This, in turn has implications for the assessment of MTBIl's communication and the identification of his loss of temper by a clinician. Unless the clinician observes MTBI1 in the presence of the environmental stressors discussed above, the communicative consequence of irritability, manifested as loss of temper, may go undetected. The value of obtaining the subjective perceptions and reports of a significant other who spends time with the individual with MTBI in a variety of personally relevant settings is thus illustrated.

\section{Word-retrieval difficulties}

In addition to MTBI1's more frequent loss of temper, P1 reported that he experiences word-retrieval difficulties:

$\therefore$ and he sometimes forgets certain words, like when a person gets older... Stupid little words, then he'll, he won't be able to get to the word. I've actually noticed that since the accident.'

'Yes, it [word-retrieval difficulty] happens regularly. It actually happens a lot. It's as if he can't place the word, or remember the thing's name.'

‘.. he searches for the word and then after a little while he'll say, "Man, there it is." After two or three minutes the word will come.'

As $\mathrm{P} 1$ emphasised the importance of the verbal expression of how one feels in her definition of communication, it was likely that she would be sensitive to any change in MTBI1's verbal communication. P1 further stated that the frustration experienced by MTBI1 when unable to express himself owing to these word-finding difficulties aggravated his loss of temper:

'No, he becomes angry with himself. He can't handle it [word-retrieval difficulty]. He doesn't like it at all.'

$\therefore$... he basically gets angry if you don't immediately know what he is talking about.' 
As word retrieval is a basic process in communication, a deficit in this area may significantly impact on an individual's overall communicative ability (King et al., 2006a). Word-retrieval difficulties typically affect communication by slowing interaction and by increasing hesitations and pauses in discourse (Hartley, 1995; Ylvisaker et al., 2001).

A number of studies have assessed word retrieval following MTBI (e.g. Barrow et al., 2003; King et al., 2006a; King et al., 2006b). Deficits in word retrieval were found to be associated primarily with increased time taken to retrieve words. These deficits were ascribed to centralised cognitive slowing and reduction in the supervisory function governing control, memory and initiation processes (Barrow et al., 2003; King et al., 2006a; King et al., 2006b). As indicated by the quote above, P1 also indicated that with time MTBI1 is able to access the target word.

King et al. (2006b) found that participants with MTBI exhibited no significant difference when compared with non-injured control participants regarding word retrieval during discourse tasks. A formal tool of word finding in discourse was used in the study by King et al. (2006b). It was argued that the cognitive load imposed by the discourse task was not sufficiently high to detect the subtle word-retrieval difficulties exhibited by the same participants during the confrontation naming task (King et al., 2006b). In contrast to these findings, wordretrieval difficulties during conversation were reported by P1. Discourse that takes place during stressful work or home activities involving multilevel processing may constitute sufficient cognitive load to elicit word-retrieval difficulties. This, again, has implications for clinicianbased assessments and highlights the value of obtaining reported observations of a significant other who interacts with the client in a variety of settings.

\section{Role change}

In her definition of communication, P1 highlighted the importance of communication within a relationship. In her description of MTBI1's communication, she indicated a change in their relationship since the accident, with her having to assume a parent role:

... after the accident I took the role of being a parent. Like he was almost like one of the children.'

'So basically he's now almost lost his role.'

Communication is ongoing and cyclical. Communication interactions or relationships evolve over time as the communicative behaviour of one individual interfaces with that of another within an ongoing situation (Hartley, 1995). The range of physical, cognitive and behavioural difficulties exhibited by the injured individual may result in a loss of peer-based and reciprocal relationships, with the spouse often being forced to take on a parental role (Kreutzer et al., 1994a). Role change experienced by spouses of individuals who have sustained a TBI has been reported in the literature and is considered to be a reason for the increased stress, depression and anxiety experienced by the spouse (e.g. Kreutzer et al., 1994a; Leathem, Heath \& Woolley, 1996).

In summary, P1 reported changes in MTBI1's communication since his accident. These changes included more frequent loss of temper, particularly in the presence of environmental factors including children and the use of alcohol. She also reported word-retrieval difficulties, as well as a change in roles with her having to assume the role of parent. Valuable information regarding MTBI1's communication was provided by $\mathrm{P} 1$ which might not have been obtained through the administration of formal tools in unnatural settings, or even through clinician-based observation.

\section{Participant 2}

When asked to describe her view of what communication entails, P2 placed emphasis on verbal expression:

'For me talking stands above everything.'

P2 also made reference to communicative behaviour as reflecting one's attitude:

'... your attitude of how you behave and what you radiate as a person.'
Like P1, P2 referred to communication within the context of relationships:

'You must have good communication to build up a good relationship ...'

Given P2's views on communication, she was likely to be sensitive to any changes in MTBI2's verbal expression, attitude and behaviour or the influence of these changes on his relationships.

When asked to describe MTBI2's communication, P2 stated that her husband likes to speak and that he likes to express his emotions:

'He likes to talk. He likes to express his emotions, by talking and also by showing how he feels. He's not someone who likes to keep things to himself.

Throughout the interview process, $\mathrm{P} 2$ made reference to numerous changes in MTBI2's communication interaction since the accident. Three themes were identified in the DA of P2's description of MTBI2's communication, namely adynamia, memory loss and social withdrawal.

\section{Adynamia}

According to P2, there was a change in MTBI2's drive and motivation since the accident. She described this change in the following way:

'He is still a perfectionist, but he'll sometimes still say, "Ag no, I don't feel like doing that now." That little spark that should be there is no longer there.'

'He doesn't have that motivation.'

'The driving power is gone.'

'Because he'd go and sit and sit still for hours and do nothing, but it didn't bother him ...'

'Yes, and that's not how he was. He was always busy, always kept busy.'

A lack of drive or motivation may not be considered by everyone to constitute a communication difficulty. However, in her description of what communication entails, $\mathrm{P} 2$ stated that communication represents one's attitude and behaviour. Therefore, any changes in MTBI2's behaviour or attitude were likely to have been noticed by P2 and reported by her in her description of his communication.

Lack of motivation, as described by the term adynamia, often occurs in individuals who have been affected by TBI (Hartley, 1995). The basal ganglia and their connections to the limbic system are regions in the brain that are involved in motivation. Because of the likelihood of damage to the anterior and mesial temporal lobe (part of the limbic system) and to the basal ganglia, changes in motivation and emotional responses within subcortical and limbic input are common after TBI (Hartley, 1995; Ylvisaker et al., 2001). Despite having sustained a mild brain injury, MTBI2 reportedly also exhibited changes in motivation.

Individuals with executive dysfunction may also exhibit adynamia (Hartley, 1995). The frontal lobes modulate and regulate the expression of internal drives and affective states. Depending on the nature of their injury, individuals with executive dysfunction may be unable to formulate and initiate goal-directed behaviour, to the point where expression of emotion or desire is lacking (Hartley, 1995). As stated, executive dysfunction is a common consequence of MTBI and can have far-reaching effects on ability to function in daily life, on job performance, and on interpersonal relationships (Kim et al., 2009; McDonald, et al., 2002). In the case of P2, MTBI2's loss of drive and motivation affected their relationship. She emphasised that MTBI2 has made progress with regard to his ability to start something and finish it. However, this change in her husband remained an adjustment for her:

'Ag, yes, it's going a lot, he's probably actually quite fine now to me, it was more the first year and a half was a bit, you could notice it [adynamia] easily ... it was sometimes very frustrating.'

'But it's sometimes just an adjustment for a person from how he was to what he was then.' [after the accident]

\section{Memory loss}

P2 reported a change in MTBI2's memory since the MTBI:

'Yes, you know, with regard to memory, this is actually a thing he ... he genuinely always had a memory like an elephant, but I don't know, 
these days you can tell him something and he will swear high and low that you didn't tell him.'

'He still has blanks and at times there are things he cannot really remember'

'Yes, ag, things like places we've been to ... Yes, small silly things that he generally would have remembered.'

Residual memory problems in MTBI typically resolve after 3 months. However, impairment in retention can persist (Levin, 1989). The effect of memory loss on communication includes slowed interaction, repetition in conversations and social breakdown (Ylvisaker et al., 2001). Although individuals with MTBI often score within normal limits on standard memory tests, close relatives frequently report considerable everyday memory problems (Kim et al., 2009). This again supports the notion that information regarding the injured individual's functioning in daily, natural settings is essential in the identification of difficulties that may go undetected on formal testing.

Memory difficulties in individuals with MTBI may be associated with medial temporal or diencephalic pathology (Kim et al., 2009). However, individuals with injury to the frontal lobes may also exhibit disruptions in the memory process and of the functions that facilitate memory. This is because the executive control centre controls memory processes by generating strategies to enhance storage and retrieval of information (Hartley, 1995).

\section{Social withdrawal}

P2 described MTBI2 as having become withdrawn in the first 18 months following the MTBI, participating less in social interactions:

... with regard to his communication, he was withdrawn directly after the accident. He was quieter ...'

'Yes, so he became a little more of an introvert ... and he didn't speak much at that stage ...'

'It was frustrating at times because he had always spoken a lot and always said how he felt and what he was thinking and explained his reasoning ...'

The reasons for MTBI2's reduced social interaction after his accident are unclear. This social withdrawal may be a consequence of his adynamia, or lack of motivation. Motivation influences an individual's attentional processes and thereby affects social interaction by either dampening or stimulating efforts at processing appropriate responses (Prigatano, 1987). Parker (1996) also reported that reduced motivation after TBI can impair efforts at social interest within individuals. In her definition of communication, P2 emphasised that in addition to verbal expression, behaviour also contributes to an individual's communication. The possibility exists that MTBI2's adynamia affected his behaviour, resulting in social withdrawal.

In summary, when viewed from the perspective of P2, MTBI2's communication interaction appears to have been affected by adynamia, memory loss and social withdrawal. P2 stated that there have been improvements with regard to MTBI2's drive and motivation as well as his social interaction, and that these two aspects of his communication were most problematic in the months following the accident. His memory difficulties, however, appear to have persisted over the 3 years following his accident.

\section{Table III. Summary of the themes identified from the participants' perspectives of communication after MTBI}

\begin{tabular}{ll} 
P1 & P2 \\
Loss of temper & Adynamia \\
Word retrieval difficulties & Memory loss \\
Role change & Social withdrawal \\
\hline
\end{tabular}

Table III summarises the themes identified from $\mathrm{P} 1$ and $\mathrm{P} 2$ 's perceptions of their spouses' communication after MTBI.

\section{Conclusion}

The results of this study show that the brain injury was perceived by both participants to have affected communication interaction of the individuals with MTBI. The results further show that the perceived effect of the injury on communication was not the same for each individual with MTBI. In certain cases, the communicative consequences of the MTBI (for example, the frequent loss of temper reported by $\mathrm{P} 1$ ) appeared to be the product of the interaction between the organic pathology and environmental factors. These findings are seen to have numerous implications for the field of speech-language pathology.

Firstly, the range of communicative difficulties reported by the participants in this study necessitates the involvement of the speech-language therapist (SLT) in the assessment and management of communication of individuals with MTBI. Individuals with MTBI usually return to work and are expected to perform at the same cognitive-communicative level as they did before their injury. The communicative demands placed on them are often higher than those placed on individuals with moderate or severe brain injuries. The SLT has a role to play in educating hospital staff as well as family members, colleagues and employers of individuals with MTBI regarding possible consequences of MTBI that may result in communication problems.

A second implication of this study pertains to the identification by the SLT of communication difficulties in individuals with MTBI. The word-finding difficulties described by $\mathrm{P} 1$ and the memory difficulties reported by $\mathrm{P} 2$ might have been identified during the administration of standardised cognitive-linguistic assessment tools, provided that the cognitive load of the assessment tasks was high enough to expose subtle difficulties in these areas. However, the more frequent loss of temper reported by the one participant, for example, is considered a product of the interaction between the (mild) organic pathology and environmental factors. The need for contextually relevant assessment procedures that focus on communication in natural and personally relevant settings is highlighted.

A third implication pertains to the management of communication difficulties associated with MTBI. In this study, information was obtained not only regarding communication of the individuals with MTBI, but also on the effect of these difficulties on interpersonal relationships and functioning within natural settings. This, in turn, has implications for the compilation of personally and contextually relevant management programmes by SLTs. Furthermore, the complex nature of the difficulties reported necessitates the involvement of a team in the management of individuals with MTBI.

The use of formal assessment procedures as well as functional rating scales is lacking in this study. Inclusion of such procedures would have facilitated triangulation of the data. It is recommended that future research into the communication of individuals with MTBI in natural settings should include a greater number of participants as well as a broader range of assessment approaches. Furthermore, investigation into the perceptions of the individual with MTBI him/herself regarding the impact of the injury on communication would provide additional valuable information.

In conclusion, the results of this study suggest that individuals with MTBI may present with communication difficulties that are evident in their natural environments. These findings support the notion that communicative competence in a range of personally relevant settings needs to be considered in the assessment and management of the communication difficulties associated with MTBI. 


\section{References}

Alexander, M.P. (1995). Mild traumatic brain injury: Pathophysiology, natural history and clinical management. Neurology, 45, 1253-1260.

American Congress of Rehabilitation Medicine [ACRM] (1993). Definition of mild traumatic brain injury. Journal of Head Trauma Rehabilitation, 8, 86-87.

Barrow, I.M., Hough, M., Rastatter, M.P., Walker, M., Holbert, D., \& Rotondo, M.F. (2003). Can withincategory naming identify subtle cognitive deficits in the mild traumatic brain-injured patient? Journal of Trauma Injury, Infection and Critical Care, 54(5), 888-897.

Cassidy, J.D., Carroll, L.J., Peloso, P.M., Borg, J., von Holst, H., Holm, L., et al., (2004). Incidence, risk factors and prevention of MTBI: Results of the WHO Collaborating Centre Task force on MTBI Journal of Rehabilitation Medicine, 43 (supplement), 28-60.

De Vos, A.S. (Ed.) (2002). Research at grass roots (2nd ed.). Pretoria: Van Schaik Publishers.

Duff, M.C., Proctor, A., \& Haley, K. (2002). Mild traumatic brain injury (MTBI): Assessment and treatment procedures used by speech-language pathologists (SLPs). Brain Injury, 16(9), 773-787.

Galski, T., Tompkins, C., \& Johnston, M.V. (1998). Competence in discourse as a measure of socia integration and quality of life in persons with traumatic brain injury. Brain Injury, 12, 769-782.

Green, B.S., Stevens, K.M. \& Wolfe, T.D.W. (1997). Mild traumatic brain injury: A therapy and resource manual. San Diego: Singular Publishing Group, Inc.

Hanna-Pladdy, B., Berry, Z.M., Bennett, T., Phillips, H.L., \& Gouvier, W.D. (2001). Stress as a diagnostic challenge for postconcussive symptoms: Sequelae of mild traumatic brain injury or physiologica stress response. The Clinical Neuropsychologist, 15(3), 289-304.

Hartley, L.L. (1995). Cognitive communicative abilities following brain injury: A functional approach. California: Singular Publishing Group, Inc.

Jaworski, A., \& Coupland, N. (1999). Introduction: Perspectives on discourse analysis. In A. Jaworski \& N. Coupland (Eds.). The discourse reader. London \& New York: Routledge.

Kim, S.-J., Kim, O.-L., Seo, W.-S., Koo, B.-H., Joo, Y., \& Bai, D.-S. (2009). Memory dysfunction after mild and moderate traumatic brain injury: Comparison between patients with and without frontal lobe injury. Journal of the Korean Neurosurgical Society, 46, 459-467.

King, K.A., Hough, M.S., Vos, P., Walker, M.M., \& Givens, G. (2006a). Word retrieval following mild TBI: Implications for categorical deficits. Aphasiology, 20(2/3/4), 233-245.

King, K.A., Hough, M.S., Walker, M.M., Rustatter, M., \& Holbert, D. (2006b). Mild traumatic brain injury Effects on naming in word retrieval and discourse. Brain Injury, 7(20), 725-732.

Kreutzer, J.S., Gervasio, A.H., \& Camplair, P.S. (1994a). Primary caregivers' psychological status and family functioning after traumatic brain injury. Brain Injury, 8(3), 197-210.

Kreutzer, J.S., Gervasio, A.H., \& Camplair, P.S. (1994b). Patient correlates of caregivers' distress and family functioning after traumatic brain injury. Brain Injury, 8(3), 197-210.

Kvale, S. (1996). InterViews: An introduction to qualitative research. California: Sage Publishers.

Kwok, F.Y., Lee, T.M.C., Leung, C.H.S., \& Poon, W.S. (2008). Changes of cognitive functioning following mild traumatic brain injury over a 3-month period. Brain Injury, 22(10), 740-751.

Leach, L.R., Frank, D.E., Bouman, D.E., \& Farmer, J. (1994). Family functioning, social support and depression after traumatic brain injury. Brain Injury, 8(7), 599-606.

Leathem, J., Heath, E., \& Woolley, C. (1996). Relatives' perceptions of role change, social support and stress after traumatic brain injury. Brain Injury, 10(1), 27-38.

Leininger, B.E., Gramling, S.E., Farrell, A.D., Kreutzer, J.S., \& Peck, E.A. (1990). Neuropsychological deficits in symptomatic minor head injury patients after concussion and mild concussion. Journal of Neurology, Neurosurgery and Psychiatry, 53, 293-296.

Levin, H.S. (1989). Memory deficit after closed-head injury. Journal of Clinical and Experimental Neuropsychology, 12(1), 129-153.

Lincoln, Y.S., \& Guba, E.G. (1985). Naturalistic Inquiry. California: Sage Publications.
Lomas, J., Pickard, L., Bester, S., Elbard, H., Finlayson, A., \& Zoghaib, C. (1989). The communicative effectiveness index: Development and psychometric evaluation of a functional communication measure for adult aphasia. Journal of Speech and Hearing Disorders, 54, 113-124.

Mathias, J.L., Beall, J.A., \& Bigler, E.D. (2004). Neuropsychological and information processing deficit following mild traumatic brain injury. Journal of the International Neuropsychological Society, 10 , 286-297.

McAllister, T.W., \& Arciniegas, D. (2002). Evaluation and treatment of postconcussive symptoms. NeuroRehabilitation, 17, 265-283.

McDonald, B.C., Flashman, L.A., \& Saykin, A.J. (2002). Executive dysfunction following traumatic brain injury: Neural substrates and treatment strategies. NeuroRehabilitation, 17, 333-344.

Parker, R.S. (1996). The spectrum of emotional distress and personality changes after minor head injury incurred in a motor vehicle accident. Brain Injury, 10(4), 298-302.

Potter, J., \& Wetherell, M. (1987). Discourse and social psychology: Beyond attitudes and behaviours. London: Sage Publications.

Prigatano, G.P. (1987). Personality and psychosocial consequences after brain injury. In M. Meier, A. Benton \& L. Diller (Eds.). Neuropsychological Rehabilitation. New York: Guilford Press.

Prutting, C.A. (1982). Pragmatics as social competence. Journal of Speech and Hearing Disorders, 47(2), 123-134.

Prutting, C.A., \& Kirchner, D.M. (1987). A clinical appraisal of the pragmatic aspects of language. Journal of Speech and Hearing Disorders, 52(2), 105-119.

Satz, P., Alfano, M.S., Light, R., Morgenstern, H., Zaucha, K., Asarnow, R.F., \& Newton, S. (1999). Persisten post concussive syndrome: A proposed methodology and literature review to determine the effects, if any, of mild head and other bodily injury. Journal of Clinical and Experimental Neuropsychology $5(21), 620-628$

Snow, P., \& Ponsford, J. (1995). Assessing and managing changes in communication and interpersonal skills following TBI. In J. Ponsford (Ed.). Traumatic brain injury rehabilitation for everyday adaptive living. East Essex: Lawrence Erlbaum Associates.

Strydom, H. (2005). Sampling and sampling methods. In A. S. de Vos, H. Strydom, C. B. Fouché \& C. S. L Delport (Eds.). Research at grass roots: For the social sciences and human service professions (3rd ed.). Pretoria: Van Schaik Publishers.

Tay, S.Y., Ang, B.T., Lau, X.Y., Meyyappan, A., \& Collinson, S.L. (2010). Chronic impairment of prospective memory after mild traumatic brain injury. Journal of Neurotrauma, 27, 77-83.

Titscher, S., Meyer, M., Wodak, R., \& Vetter, E. (2000). Methods of text and discourse analysis. London Sage Publications.

Voller, B., Benke, T., Benedetto, K., Schnider, P., Auff, E., \& Aichner, F. (1999). Neuropsychological, MR and EEG findings after very mild traumatic brain injury. Brain Injury, 13(10), 821-827.

Vyncke, I.O. (2000). Discourse of subjects with early onset and late onset Parkinson's disease: A linguistic and motor speech profile. Unpublished D.Phil. dissertation. Johannesburg: University of the Witwatersrand.

Wetherell, M., Taylor, S., \& Yates, S.J. (2001). Discourse as data: A guide for analysis. Bath: Bath Press.

Whelan, B., Murdoch, B.E., \& Bellamy, N. (2007). Delineating communication impairments associated with mild traumatic brain injury: A case report. Journal of Head Trauma Rehabilitation, 22(3), 192197.

Willig, C. (1999). Introduction: making a difference. In C. Willig (Ed.). Applied discourse analysis: Social and psychological interventions. Buckingham: Open University Press.

Ylvisaker, M., \& Feeney, T. (1998). Collaborative brain injury intervention: Positive everyday routines. California: Singular Publishing Group.

Ylvisaker, M., Szekeres, S., \& Feeney, T. (2001). Communication disorders associated with traumatic brain injury. In $\mathrm{R}$. Chapey (Ed). Language intervention strategies in aphasia and related neurogenic communication disorders (4th ed.). Philadelphia: Lippincott Williams \& Wilkins. 